\title{
Active-Transient Liquid Phase (A-TLP) Bonding of Pure Aluminum Matrix Composite Reinforced with Short Alumina Fiber Using Al-12Si- $x$ Ti Foils as Active Interlayer
}

\author{
GUIFENG ZHANG, WEI SU, and AKIO SUZUMURA
}

To optimize both the interlayer composition design route and pressure for joining aluminum matrix composite reinforced with short alumina fiber (as-cast 30 vol pct $\mathrm{Al}_{2} \mathrm{O}_{3 \mathrm{sf}} / \mathrm{Al}$ ), traditional transient liquid phase (TLP) bonding using Al-12Si and $\mathrm{Cu}$ interlayer and active-TLP (A-TLP) bonding using an active Ti-containing interlayer (Al-12Si- $x \mathrm{Ti}, x=0.1,0.5$, and $1 \mathrm{wt}$ pet) under the same condition $\left[883 \mathrm{~K}\left(610^{\circ} \mathrm{C}\right) \times 30\right.$ minutes $\times 1$ or $0.015 \mathrm{MPa}$ in flowing argon] were compared in terms of interfacial wettability, bond seam microstructure, shear strength, and fracture path. It was found that not only the Ti content but also the pressure are critical factors affecting interfacial wettability and bond seam microstructure. The improvement in wettability by adding Ti as an active element were confirmed by reduction of expulsion of liquid interlayer, elimination of interfacial gap, higher shear strength and favorable fracture path (partially through bond seam and the composite). Because of the incubation period for wetting, reducing the pressure after melting of the interlayer could further increase joint shear strength by thickening the remaining bond seam of solid-solution matrix and decreasing fraction of the in situ newly formed Al-Si-Ti IMC phase (short bar shape) within the bond seam. The maximum shear strength of $88.6 \mathrm{MPa}$ (99 pct of the as-cast composite) was obtained by adding trace $\mathrm{Ti}$ content $(0.5 \mathrm{Ti}$ wt pct) addition and using low pressure $(0.015 \mathrm{MPa})$. The results showed that suitable combination of $\mathrm{Ti}$ content and pressure pattern is required for improving both wettability and bond seam microstructure.

DOI: $10.1007 / \mathrm{s} 11663-015-0371-5$

(C) The Author(s) 2016. This article is published with open access at Springerlink.com

\section{INTRODUCTION}

Although the addition of discontinuous ceramic reinforcement into an aluminum matrix can improve the stiffness, wear resistance, and compressive strength at an elevated temperature of monolithic aluminum matrix, the presence of ceramic reinforcement in aluminum metal matrix composites (Al-MMCs) deteriorates the weldability primarily because of the intense and detrimental interfacial reaction between ceramic particles and superheated Al melt in arc welding. ${ }^{[1-4]}$ Thus, friction-stir welding and brazing are promising methods for joining discontinuously reinforced Al-MMCs. ${ }^{[5-7]}$ Because both $\mathrm{Al}$ matrix and ceramic particles coexist on the surface of Al-MMCs to be joined, ${ }^{[8]}$ the brazeability of Al-MMCs is determined by the wettability at two kinds of microinterfaces: matrix/brazing filler metal (M/ $\mathrm{M})$ and reinforcement/brazing filler metal $(\mathrm{R} / \mathrm{M}) \cdot{ }^{[7]}$

GUIFENG ZHANG, Associate Professor, and WEI SU, Graduate Student, are with the State Key Laboratory for Mechanical Behavior of Materials, Xi'an Jiaotong University, Xi'an 710049, P.R. China. Contact e-mail: gfzhang@mail.xjtu.edu.cn. AKIO SUZUMURA, Professor, is with the Department of Mechanical and Aerospace System Engineering, Tokyo Institute of Technology, Tokyo 152-8552, Japan.

Manuscript submitted July 26, 2014

Article published online February 10, 2016.
The first factor governing the wettability at both $\mathrm{M} / \mathrm{M}$ and $\mathrm{R} / \mathrm{M}$ interfaces is the composition design of the brazing filler metal. The published brazing filler metals can be classified into three groups with different melting regions: (I) $\mathrm{Zn}-\mathrm{Al}(-\mathrm{Cu}),{ }^{[9-12]}$ (II) $\mathrm{Al}-12 \mathrm{Si}$ (4047), ${ }^{[13,14]}$ and $\mathrm{Al}-11.6 \mathrm{Si}-1.5 \mathrm{Mg}$ [4N04 with a melting range of $840 \mathrm{~K}$ to $850 \mathrm{~K}\left(567^{\circ} \mathrm{C}\right.$ to $\left.\left.577^{\circ} \mathrm{C}\right)\right]$ systems, ${ }^{[7,8,14-17]}$ and (III) $\mathrm{Al}-28 \mathrm{Cu}-5 \mathrm{Si}-2 \mathrm{Mg}$ with a melting range of $798 \mathrm{~K}$ to $808 \mathrm{~K}\left(525{ }^{\circ} \mathrm{C} \text { to } 535^{\circ} \mathrm{C}\right)^{[18,19]}$ and $\mathrm{Al}-24 \mathrm{Cu}-5-$ Si-0.5Ni. ${ }^{[20]}$ For Zn-based filler metals, flux (hygroscopic chlorides), ${ }^{[9]}$ ultrasonic vibration, ${ }^{[10,11]}$ or stirring ${ }^{12]}$ must be introduced to remove oxide film on the Al matrix surface at a lower joining temperature in air. For Al-Si brazing filler metal, an interfacial gap $(1 \mu \mathrm{m})$ at $\mathrm{R} / \mathrm{M}$ interface was observed, ${ }^{[13]}$ and it was easy to discharge from the joint interface under pressure, leading to the lack of dissolution of Al matrix. For Al-Si-Mg brazing filler metal, Suzumura et al. first demonstrated that $\mathrm{Al}-12 \mathrm{Si}-1.5 \mathrm{Mg}$ filler metal could spread on the surface of $\mathrm{Al}$ matrix composite reinforced by a short alumina fiber while Al-12Si remained in the original shape of wire in the wettability test in a vacuum. ${ }^{[14]}$ Moreover, although $\mathrm{Al}-12 \mathrm{Si}-1.5 \mathrm{Mg}$ brazing filler metal was able to wet Al matrix with rougher surface $^{[14]}$ and the interface void can be eliminated with appropriate pressure ${ }^{[17]}$ the poor wettability at the $\mathrm{R} / \mathrm{M}$ interface led to a decrease in joint strength with increase 
in volume fraction of reinforcement. ${ }^{[7,15]}$ For $\mathrm{Al}-25 \mathrm{Cu}-$ $5 \mathrm{Si}-2 \mathrm{Mg}$ (wt pct) braze with a low melting range from $798 \mathrm{~K}\left(525^{\circ} \mathrm{C}\right)$ to $808 \mathrm{~K}\left(535^{\circ} \mathrm{C}\right)$, chloride flux (rather than fluoride flux) or relative high pressure (2 $\mathrm{MPa})$ was recommended when brazing 15 vol pet $\mathrm{SiC}_{\mathrm{p}} / 6061 \mathrm{Al}$ in air or brazing 10 vol pet $\mathrm{SiC}_{\mathrm{p}} / 2024 \mathrm{Al}$ in vacuum, respectively, to achieve better wettability. ${ }^{[18,19]}$ In the wettability test using flux, the $\mathrm{Al}-28 \mathrm{Cu}-5 \mathrm{Si}-2 \mathrm{Mg}$ brazing filler metal could spread on a substrate of $15 \mathrm{vol}$ pct $\mathrm{SiC}_{\mathrm{p}} / 6061$ composite, but it failed to spread on the composite substrate containing 30 vol pet $\mathrm{SiC}$ particles. $^{[19]}$

As an alternative process to conventional soldering and brazing, transient liquid phase (TLP) bonding using an interlayer containing sufficient melting point depressant (MPD, eutectic former of $\mathrm{Al}$ ), such as $\mathrm{Cu},{ }^{[21-24]} \mathrm{Ag},{ }^{[25]}$ and $\mathrm{Ni},{ }^{[26]}$ can remove oxide film on the Al matrix via an undermining mechanism ${ }^{[27-31]}$ and can finally obtain an Al-based solid-solution bond seam after isothermal solidification and homogenization. ${ }^{[32-34]}$ However, poor wettability at the $\mathrm{R} / \mathrm{M}$ interface and ceramic particle segregation at the center line of bond seam significantly limit the properties of TLP bonded joints. Of the two problems, poor wettability is more important than particle segregation because even if the particles can be distributed uniformly in the bond seam, poor wettability at the $\mathrm{R} / \mathrm{M}$ interface will result in an interfacial gap between the ceramic particle and bond matrix, significantly damaging joint strength.

For counteracting particle segregation, many studies have been performed, in which thinner $\mathrm{Cu}$ foil ${ }^{[23,24]}$ and $\mathrm{Al}-\mathrm{Cu}$ binary interlayer ${ }^{[35]}$ were suggested to reduce particulate segregation by limiting matrix dissolution width. Also, $\mathrm{Ni}$ or $\mathrm{Sn}$ was added in the $\mathrm{Cu}$ interlayer, preparing $\mathrm{Cu} / \mathrm{Ni} / \mathrm{Cu}$ sandwich foil ${ }^{[36]}$ and mixed $\mathrm{Cu}-\mathrm{Ni}$ powder $^{[37]}$ or $\mathrm{Cu} / \mathrm{Sn} / \mathrm{Cu}^{[38]}$ as modified interlayers to suppress particle segregation. Although the achieved joint efficiency for mixed $\mathrm{Cu}-\mathrm{Ni}$ powder interlayer (84 pct of parent 13 vol pet $\mathrm{SiC}_{\mathrm{p}} / 6061 \mathrm{Al}$ ) was much higher than that for the $\mathrm{Cu} / \mathrm{Ni} / \mathrm{Cu}$ stacked foil interlayer (68 pct), it was still lower than that obtained with a pure $\mathrm{Cu}$ interlayer. ${ }^{[37]}$ Because of the presence of a naked $\mathrm{SiC}$ particle on the fracture surface, one reason for such low joint efficiency was that the failure primarily occurred through decohesion at the $\mathrm{SiC} / \mathrm{M}$ interface. ${ }^{[37]}$

In recent years, some researchers succeeded in reinforcing bond seams by externally adding a ceramic particle into the monolithic interlayer. Yan et al. developed a $\mathrm{SiC}$ particle-reinforced $\mathrm{Zn}-4.6 \mathrm{Al}-3 \mathrm{Cu}$ (wt pct) filler metal to join 20 vol pet $\mathrm{SiC}_{\mathrm{p}} / \mathrm{A} 356$ composite at $693 \mathrm{~K}\left(420^{\circ} \mathrm{C}\right)$ in air, and a dramatic increase in bond strength $(\sim 30 \mathrm{MPa})$ occurred as the ultrasonic vibration time exceeded 2 seconds because of the penetration of liquid $\mathrm{Zn}$ into the A356 substrate, partial melting of A356 matrix, and homogeneous distribution of particles with the aid of ultrasonic vibration. ${ }^{[39]}$ Cooke added nanoscale $\mathrm{Al}_{2} \mathrm{O}_{3}$ particles into 5 - $\mu$ m-thick $\mathrm{Ni}$ coating (in 18 vol pct) and then increased joint shear strength by $20 \mathrm{MPa}$ in TLP bonding of 15 vol pet $\mathrm{Al}_{2} \mathrm{O}_{3 \mathrm{p}} / 6061 \mathrm{Al}$ composite at the temperature of $873 \mathrm{~K}\left(600^{\circ} \mathrm{C}\right)$ [which is slightly higher than Al-Ni-Si ternary eutectic temperature of $838 \mathrm{~K}\left(565^{\circ} \mathrm{C}\right)$ ] for 10 minutes in a vacuum.
The favorite shear strength was attributed to the formation of ternary Al-Ni-Si eutectic liquid, the nanoparticles arranged along grain boundary of bond matrix, and their pinning effect. ${ }^{[40]}$

On the other hand, until now, a few studies on the development of an active filler metal for improving wettability have been reported. Weng and Chuang early stated that Sn10Ag4Ti (wt pct) active filler metal could wet the $\mathrm{Al}_{2} \mathrm{O}_{3 \mathrm{p}} / 6061 \mathrm{Al}$ composite well for the reason that the Sn10Ag4Ti filler metal begins to adhere to the $\mathrm{Al}_{2} \mathrm{O}_{3}$ particulate aligned along the joining surface above $873 \mathrm{~K}\left(600{ }^{\circ} \mathrm{C}\right) .{ }^{[41]}$ Lugscheider et al. developed an active solder of $\mathrm{Sn} 91.8 / \mathrm{Ag} 4 / \mathrm{Ti} 4 / \mathrm{Ga} 0.1 / \mathrm{Ce} 0.1$ to a wet silicon substrate in microsystem fabrication. ${ }^{[42,43]}$ Huang et al. added $\mathrm{Ti}$ powder $(<3 \mathrm{wt} \mathrm{pct})$ into a mixed Al-Si-SiC powder as an interlayer to improve the wettability of the SiC powder by the liquid Al-Si alloy formed by eutectic reaction in the powder interlayer. They claimed that a dense joining layer was formed for connecting the two $\mathrm{SiC}_{\mathrm{p}} / 6063$ composites, and no obvious $\mathrm{SiC}$ segregation was found in the bond seam. ${ }^{[4]}$

In recent years, the present authors' group has attempted to add active elements (which can react with ceramic reinforcement, e.g., $\mathrm{Ti}, \mathrm{Zr}, \mathrm{Li}$, or $\mathrm{Mg}$ ) into a general Al-based brazing filler metal to improve the wettability at the $\mathrm{R} / \mathrm{M}$ interface, and the TLP bonding process using the Ti-containing active interlayer is called active-TLP bonding (A-TLP) process by the present authors' group. ${ }^{[45]}$ For a high-volume-fraction $\mathrm{SiC}$ particle (70 vol pct)-reinforced A356 composite, it was found that dual-active elements of $\mathrm{Mg}$ and $\mathrm{Ti}$ are essential for improving the wettability at $\mathrm{M} /$ $\mathrm{M}$ and at $\mathrm{R} / \mathrm{M}$ interfaces, respectively. ${ }^{[46]}$ For a low-volume-fraction $\mathrm{SiC}$ particle (10 vol pct)-reinforced A356 composite, it was found that $\mathrm{Al}-\mathrm{Cu}-\mathrm{Ti}$ ternary active interlayer can wet both $\mathrm{A} 356$ matrix and $\mathrm{SiC}$ particle, and it can produce a reinforcing phase of in situ small and dispersive Al-Si-Ti intermetallic phase within the TLP bond seam. ${ }^{[47]}$ For a medium-volume-fraction short alumina fiber (30 vol pct)-reinforced pure Al composite, in our previous study evaluating the wettability using the sessile drop method, ${ }^{[4]}$ it was found that the Al-12Si-1Ti active filler metal penetrated in situ into the composite substrate faster and covered $\mathrm{Al}_{2} \mathrm{O}_{3}$ short fiber closely, and a bare $\mathrm{Al}_{2} \mathrm{O}_{3}$ short fiber was difficult to observe on the substrate surface. For the common Al-12Si brazing filler metal, the interfacial gaps at the R/M interface could not be eliminated due to poor wettability.

Following our previous study on wettability, ${ }^{[48]}$ this work aims to further demonstrate the beneficial effect of adding $\mathrm{Ti}$ in trace levels into the interlayer on improving the microstructure and property of joints.

\section{EXPERIMENTAL}

The aluminum matrix composite used was fabricated by pressure casting, ${ }^{[25]}$ which consisted of pure Al matrix (to simplify analysis) and short ceramic fiber reinforcement with a medium volume fraction of 30 vol pct and an average size of $3.6 \mu \mathrm{m}$ in diameter and $140 \mu \mathrm{m}$ in length. The ceramic reinforcement consisting of 85 wt pct $\mathrm{Al}_{2} \mathrm{O}_{3}$ and 15 wt pct $\mathrm{SiO}_{2}$ (see Figure 1) had 


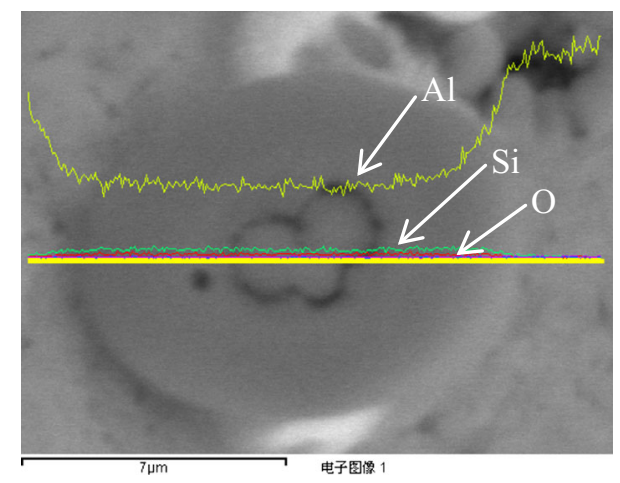

Fig. 1-EDS line scan analysis results showing the presence of both $\mathrm{Si}$ and $\mathrm{Al}$ in the chopped oxide fiber reinforcement.

a higher mole ratio of alumina to silica $(\sim 3: 1)$ than typical mullite $\left(3 \mathrm{Al}_{2} \mathrm{O}_{3} \cdot 2 \mathrm{SiO}_{2}\right)$, and then it was considered to be an alumina-based short fiber, denoted as $\mathrm{Al}_{2} \mathrm{O}_{3 \mathrm{~s}} / \mathrm{Al}$. It was reported that the presence of $\mathrm{SiO}_{2}$ layer on $\mathrm{SiC}$ surface formed by passive oxidation of $\mathrm{SiC}$ not only could be effective for prohibiting a direct contract between $\mathrm{SiC}$ and $\mathrm{Al}$, but also it favored a reactive wetting between $\mathrm{Al}$ and $\mathrm{SiC} \cdot{ }^{[49-51]}$ Because of the pressure casting technique and the improved wettability between the reinforcement and pure $\mathrm{Al}$ matrix, the $\mathrm{Al}_{2} \mathrm{O}_{3 \mathrm{sf}} / \mathrm{Al}$ composite exhibited a dense interface between the $\mathrm{Al}$ matrix and the short reinforcement fiber and a high tensile strength of $173 \mathrm{MPa} \cdot{ }^{[25]}$ The shear strength of the as-cast $\mathrm{Al}_{2} \mathrm{O}_{3 \mathrm{sf}} / \mathrm{Al}$ was measured as 89.3 MPa. The samples with different sizes $(15 \times 15 \times$ $1.8 \mathrm{~mm}$ and $5 \times 5 \times 1.8 \mathrm{~mm}$ ) were polished using dry 600 -grit silicon carbide paper, cleaned by ultrasonic vibration in acetone for 5 minutes, and then assembled in overlap configuration.

A series of $100-\mu \mathrm{m}$-thick active interlayer foils of Al-12Si- $x \operatorname{Ti}(x=0,0.1,0.5$, and $1 \mathrm{wt}$ pct $)$ were developed by melting Al, Al-20Si and Al-5Ti master alloys at $1103 \mathrm{~K}\left(830^{\circ} \mathrm{C}\right)$ for 30 minute, followed by rapid solidification using rotating $\mathrm{Cu}$ wheel. Their microstructure, melting range and wetting behavior have been investigated and published elsewhere. ${ }^{[48,52]}$

The schematic illustration of the bonding system is shown in Figure 2. TLP bonding using Al-12Si and $\mathrm{Cu}$ interlayer and A-TLP bonding using an active Ti-containing interlayer (Al-12Si- $x \mathrm{Ti}, \quad x=0.1,0.5$, and $1 \mathrm{wt}$ pct) were compared in terms of interfacial wettability, bond seam microstructure, shear strength, and fracture path to clarify the beneficial effect of $\mathrm{Ti}$ addition into traditional Al-based interlayer (or brazing filler metal) and to optimize the combination of the active interlayer composition with the bonding pressure. Each bonding was performed in flowing argon (4L minute $\left.{ }^{-1}\right)$ at $883 \mathrm{~K}\left(610^{\circ} \mathrm{C}\right)$ for 30 minutes under two pressure patterns, i.e., a constant high pressure (1 MPa) like that used in general TLP bonding of metals and an initial high pressure (1 MPa) followed by a low pressure $(0.015 \mathrm{MPa})$ after melting of the interlayer to avoid discharging of the melt for the poor wetting couple. It took 5 minutes to heat the samples from room temperature to the preset bonding temperature.

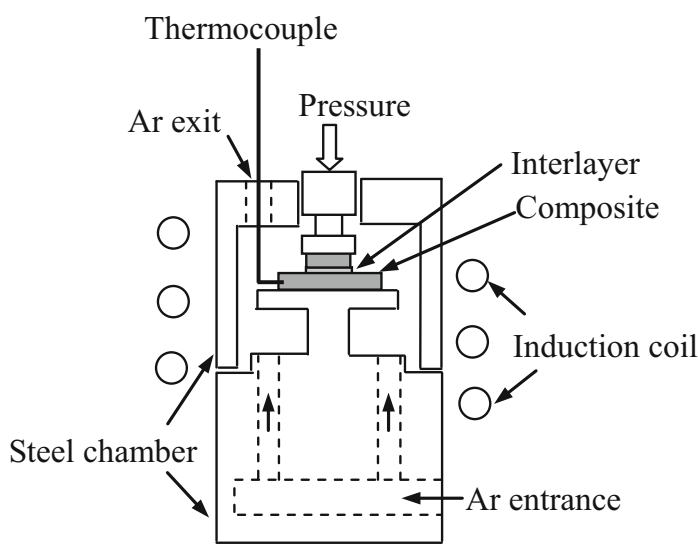

Fig. 2-Schematic of bonding apparatus.

At least four joint samples were prepared for each selected combination of parameters. Among them, three joint samples were used to evaluate joint strength by push-shear mode, and one joint sample was used to examine the microstructure. Backscattered electron (BSE) imaging was used to examine joint microstructure and fracture path, and energy-dispersive X-ray spectroscopy (EDS) was combined to investigate the diffusion result and newly formed phase. For a comparison, the popular interlayer of $\mathrm{Cu}$ foil with a thickness of 50 $\mu \mathrm{m}$ was also used at $853 \mathrm{~K}\left(580{ }^{\circ} \mathrm{C}\right)$ for 30 minutes to suppress particle segregation. Special attention was paid to the phenomena caused by $\mathrm{Ti}$ addition, including the ability to eliminate the interfacial gap at $\mathrm{R} / \mathrm{M}$ interface, the distribution feature of the active element of $\mathrm{Ti}$, and the phase constituent characterization of the bond seam.

\section{RESULTS AND DISCUSSION}

\section{A. Joint Shear Strength for Different Interlayers and Pressure Patterns}

Table I shows the variation of joint shear strengths depending on the $\mathrm{Ti}$ content and pressure pattern at $883 \mathrm{~K}\left(610^{\circ} \mathrm{C}\right)$ for 30 minutes. For the effect of $\mathrm{Ti}$ addition on improving joint properties, it can be seen that with increasing the Ti content from 0 to $0.5 \mathrm{wt}$ pct, the average joint shear strength increased from $60 \mathrm{MPa}$ to $80 \mathrm{MPa}$ for high pressure and from 75 to $89 \mathrm{MPa}$ in the case of reducing pressure after melting of the interlayer. The results clearly confirmed that adding an appropriate amount of $\mathrm{Ti}$ (e.g., trace level less than 1 wt pct) could significantly enhance the joint shear strength; namely, A-TLP bonding would be more effective over general TLP bonding for the composite containing medium volume fraction ceramic reinforcement. Unlike general TLP bonding of monolithic metal, only MPD ( $\mathrm{Si}$ ) is not enough to wet the entire interface because several ceramic reinforcements in the Al-MMC are difficult to be wetted by the Al-based interlayers. The increase in joint shear strength should be attributed primarily to the improvement in wettability by adding the active element $\mathrm{Ti}$, especially at the $\mathrm{R} / \mathrm{M}$ interface (see Section III-B). 
Table I. Effect of Ti Content and Pressure on Joint Shear Strength

\begin{tabular}{|c|c|c|c|c|c|}
\hline \multirow[b]{2}{*}{ Interlayer (Weight Percent) } & \multirow[b]{2}{*}{ Pressure (MPa) } & \multicolumn{3}{|c|}{ Shear Strength (MPa) } & \multirow[b]{2}{*}{ Average Strength $(\mathrm{MPa})$} \\
\hline & & 1 & 2 & 3 & \\
\hline \multirow[t]{2}{*}{$\mathrm{Al}-12 \mathrm{Si}$} & 1 & 47 & 65 & 70 & 60 \\
\hline & 0.015 & 74 & 75 & 76 & 75 \\
\hline \multirow[t]{2}{*}{ Al-12Si-0.1Ti } & 1 & 66 & 74 & 77 & 73 \\
\hline & 0.015 & 77 & 81 & 83 & 80 \\
\hline \multirow[t]{2}{*}{$\mathrm{Al}-12 \mathrm{Si}-0.5 \mathrm{Ti}$} & 1 & 76 & 78 & 86 & 80 \\
\hline & 0.015 & 87 & 89 & 90 & 89 \\
\hline \multirow[t]{2}{*}{ Al-12Si-1Ti } & 1 & 47 & 47 & 54 & 50 \\
\hline & 0.015 & 75 & 75 & 79 & 76 \\
\hline $\mathrm{Cu}^{*}$ & 1 & 42 & 35 & 44 & 40 \\
\hline
\end{tabular}

*Bonding condition: $1 \mathrm{MPa} \times 30 \mathrm{~min} \times 853 \mathrm{~K}\left(580^{\circ} \mathrm{C}\right)$.

In contrast, it should be noted that although Al-12Si-1Ti exhibited more favorable wettability over $\mathrm{Al}-12 \mathrm{Si}$ in a previous study, ${ }^{[48]}$ the A-TLP joint prepared with Al-12Si-1Ti showed the lowest strength. The result showed that for a high Ti content, good wettability did not consequentially imply high properties in the couples, although isothermal solidification had been completed. ${ }^{[48]}$

For the effect of reducing pressure after melting of the interlayer on improving joint properties, it can be seen that in this case, joint shear strength could be further improved by $\sim 7 \mathrm{MPa}$ for a Ti-containing active interlayer and $\sim 16 \mathrm{MPa}$ for common Al-12Si interlayer. Suzumura et al. succeeded in increasing the tensile strength of the joint of the $\mathrm{Al}_{2} \mathrm{O}_{\text {sf }} / \mathrm{Al}$ composite brazed at $893 \mathrm{~K}$ $\left(620^{\circ} \mathrm{C}\right)$ for 200 seconds in a vacuum via reducing bonding pressure (from 4 to $2 \mathrm{MPa}$ ) and inserting a 0.3 -mm-thick Al spacer to avoid discharging of the molten brazing filler metal of $\mathrm{Al}-12 \mathrm{Si}-1.5 \mathrm{Mg}$ (4N04, $0.3 \mathrm{~mm}$ in initial thickness). ${ }^{[15]}$ The improvement is effective for the composite containing low volume fraction short alumina fiber $(10,15$, and $20 \mathrm{vol}$ pct $)$, compared with the case of $30 \mathrm{vol}$ pct. ${ }^{[15]}$ The results by the author and Suzumura et al. showed that unlike TLP bonding of $\mathrm{Al}$ using $\mathrm{Cu}$ or $\mathrm{Ag}$ interlayer, for the poor wetting couple, the joint strength was sensitive to bonding pressure, and low pressure should be preferentially applied after melting of the interlayer to avoid expulsion of liquid phase, even for an active interlayer. The fact that the remaining liquid was beneficial to finally obtaining an enhanced joint suggested that there was a nonignorable incubation period for starting a wetting reaction. The presence of incubation time for a wetting reaction should be related to the presence of ceramic reinforcement. Also, a higher pressure before melting of interlayer is expected to create close contact early and widely between composite and interlayer in the solid state. ${ }^{[25]}$

In particular, the maximum shear strength $(88.6 \mathrm{MPa})$ could be obtained when using Al-12Si-0.5Ti active foil and reducing bonding pressure after melting of the interlayer. The maximum shear strength was quite close to that of the as-cast parent composites $(89.3 \mathrm{MPa}$ ), reaching 99 pct joint efficiency. The result showed the importance of a suitable combination of Ti content and pressure pattern. In principle, retaining a molten active interlayer in a required amount and for a required time (depending on volume fraction of ceramic reinforcement and incubation period) is essential for obtaining a sound joint.

\section{B. Effect of Ti Addition and Pressure on Microstructure at Interface and Bond Seam}

1. Interfacial microstructure evolution for interlayers with and without Ti

Figure 3 shows the difference in interfacial gap evolution behavior between the two cases using traditional Al-12Si and Al-12Si-1 Ti active interlayers during different holding periods (ranging from 5 seconds to 10 minutes) at $883 \mathrm{~K}\left(610^{\circ} \mathrm{C}\right)$ under $1 \mathrm{MPa}$ pressure. The improvement in wettability by adding $\mathrm{Ti}$ as active element can be demonstrated by the following two facts: rapid disappearance of interfacial gap and the presence of remaining interlayer at anywhere even under high pressure.

It is worth noting that in the early stages of the brazing process, the interfacial gap at $\mathrm{M} / \mathrm{M}$ microinterfaces for Al-12Si-1Ti foil could be eliminated much faster than that for Al-12Si foil. For example, at $500 \times$ magnification, the interfacial gap at $\mathrm{M} / \mathrm{M}$ microinterfaces for Al-12Si-1Ti foil disappeared in approximately 5 seconds (Figure 3(a)), whereas for Al-12Si foil, the interfacial gap at $\mathbf{M} / \mathbf{M}$ microinterfaces disappeared in approximately 10 minutes (Figure 3(h)). In the previous work, after the wetting test using the sessile drop method in flowing argon without any pressure,${ }^{[48]}$ the amount of the residue of molten Al-12Si was more than that of Al-12Si-1Ti, showing that Al-12Si-1Ti was able to penetrate into $\mathrm{Al}$ matrix faster than $\mathrm{Al}-12 \mathrm{Si}$. The significant reduction in the total time for eliminating interfacial gap indicated that the liquid $\mathrm{Ti}$ atoms accelerated the interfacial reaction at most $\mathrm{M} / \mathrm{M}$ microinterfaces like $\mathrm{Mg}^{[15,53]}$ and improved the wettability at $\mathrm{R} / \mathrm{M}$ microinterfaces to some extent. For Al-12Si brazing filler metal, the presence of oxide film on the molten filler metal Al-12Si surface should be primarily responsible for the long incubation period for wetting, although the reinforcement contained $\mathrm{SiO}_{2}{ }^{[54]}$ For Al-12Si-1Ti interlayer, only $\mathrm{Ti}$ can react with an ultrathin oxide film, but it cannot entirely remove the 


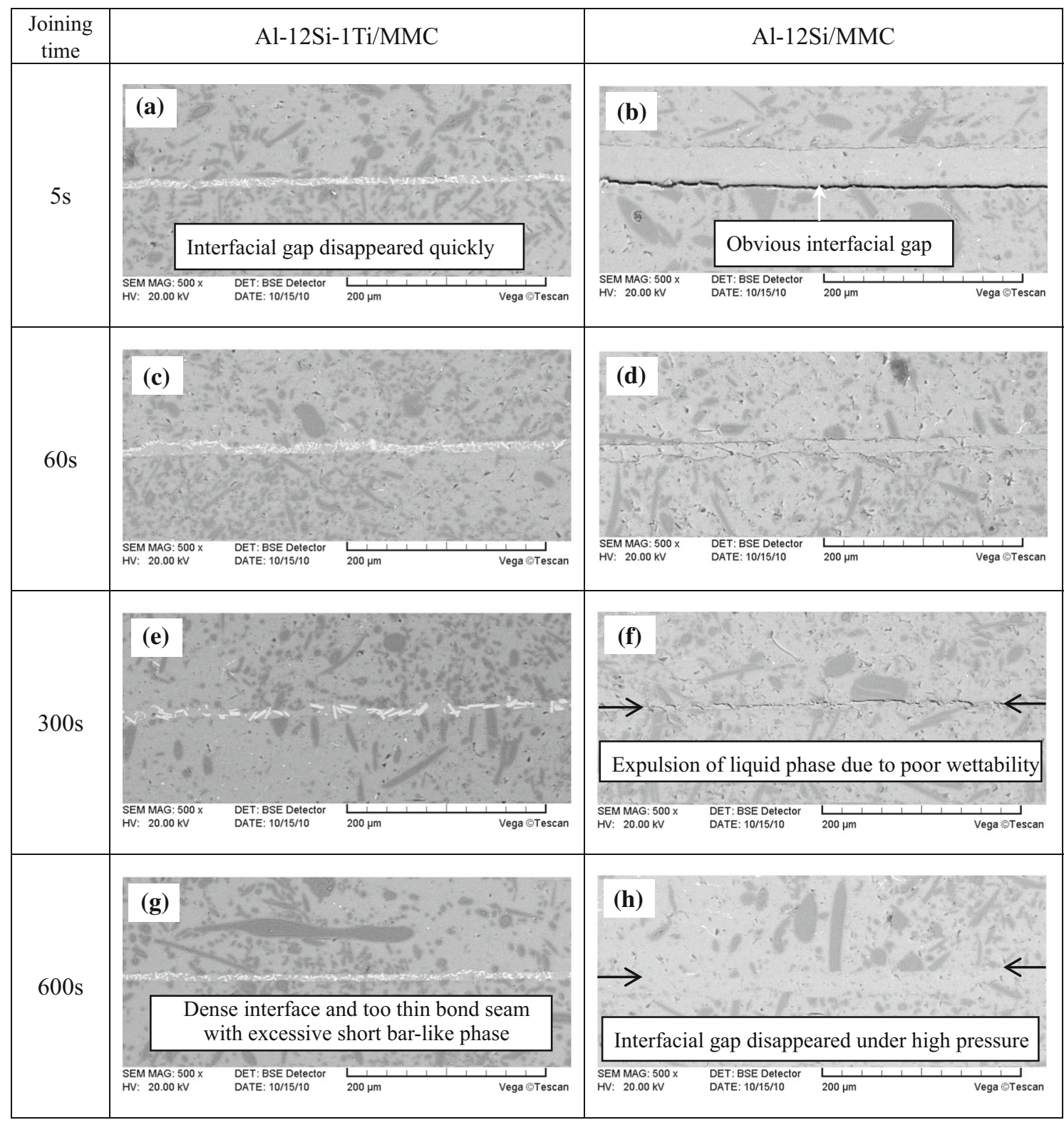

Fig. 3 - Comparison of evolution of the interfacial gap in the early stage of the joint formation using the interlayers with and without Ti under high pressure of $1 \mathrm{MPa}$ at $883 \mathrm{~K}\left(610^{\circ} \mathrm{C}\right)$.

oxide film. In contrast, Si as MPD with a relatively high content can dissolve the Al matrix significantly, achieving wetting at all $\mathrm{M} / \mathrm{M}$ microinterfaces. So, the combination of $\mathrm{Ti}$ (as active element with a trace level content) and Si (as MPD with a relatively high content) could remove oxide film rapidly and extensively in the A-TLP bonding process. Namely, active Ti atoms in the molten state can react with oxide films at the surfaces of both the molten braze and solid matrix, disrupting the integrity of the oxide films, rapidly establishing initial diffusion path for MPD of $\mathrm{Si}$, and subsequently promoting wetting at the $\mathrm{M} / \mathrm{M}$ microinterface.

In the A-TLP bonding process, the establishment of an initial diffusion path for MPD does not rely only on the cracking of the oxide film caused by the mismatch in coefficient of thermal expansion between metal and its oxide film. The active element Ti could also play a prior and chemical role in disrupting oxide film and establishing initial diffusion path for MPD at M/M micro-interface. The important feature of active element would be valuable for joining Al-MMCs containing medium and high volume fraction ceramic reinforcement.

The other evidence for improvement in wettability was that the molten active interlayer Al-12Si-1Ti was difficult to extrude completely from the interface anywhere for any period under high pressure. For Al-12Si filler metal, the unbonded areas without filler metal were observed sometimes, especially at the $\mathrm{R} / \mathrm{M}$ microinterface with relatively large ceramic particles. The poor wettability and resultant long incubation period should be responsible for extrusion of the liquid phase from faying surfaces.

On the other hand, large numbers of Ti-containing short bar-like intermetallic compounds (IMCs, white 
phase in Figure 3) were formed in situ in the bond seam for Al-12Si-1Ti layer, and their size could reach the bond seam thickness. Moreover, it seems that the number of the Ti-containing short bar-like IMCs did not decrease with increasing holding time. The results suggested that Ti was hard to diffuse into Al matrix, and then excessive $\mathrm{Ti}$ tended to form aluminide in bond seam, because (I) Ti has little solubility in $\mathrm{Al}^{[55]}$ and (II) $\mathrm{Ti}$ is a melting point increaser (MPI) for Al rather than a MPD. ${ }^{[47,48]}$
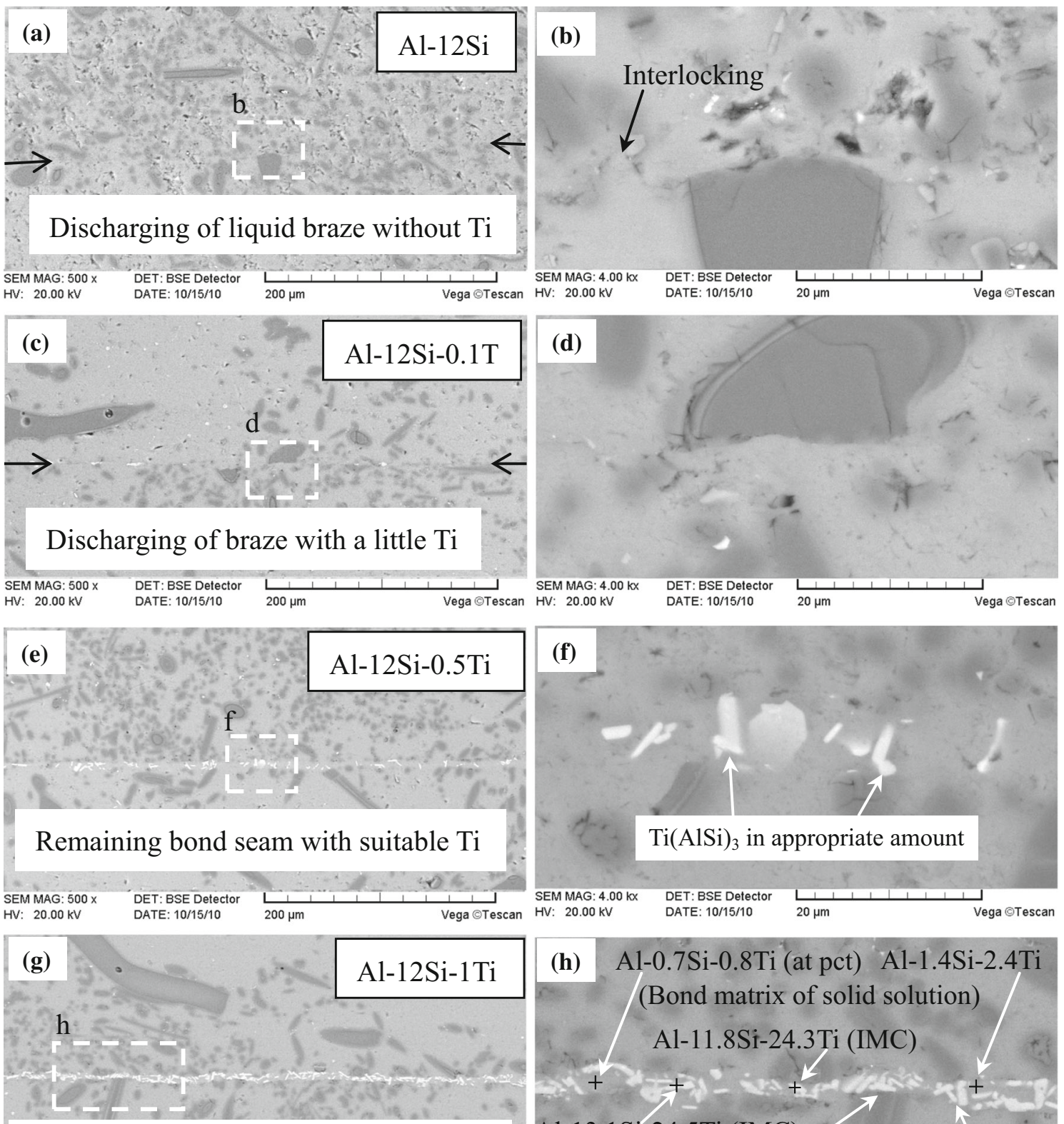

Excessive Ti-containing IMC phase in bond
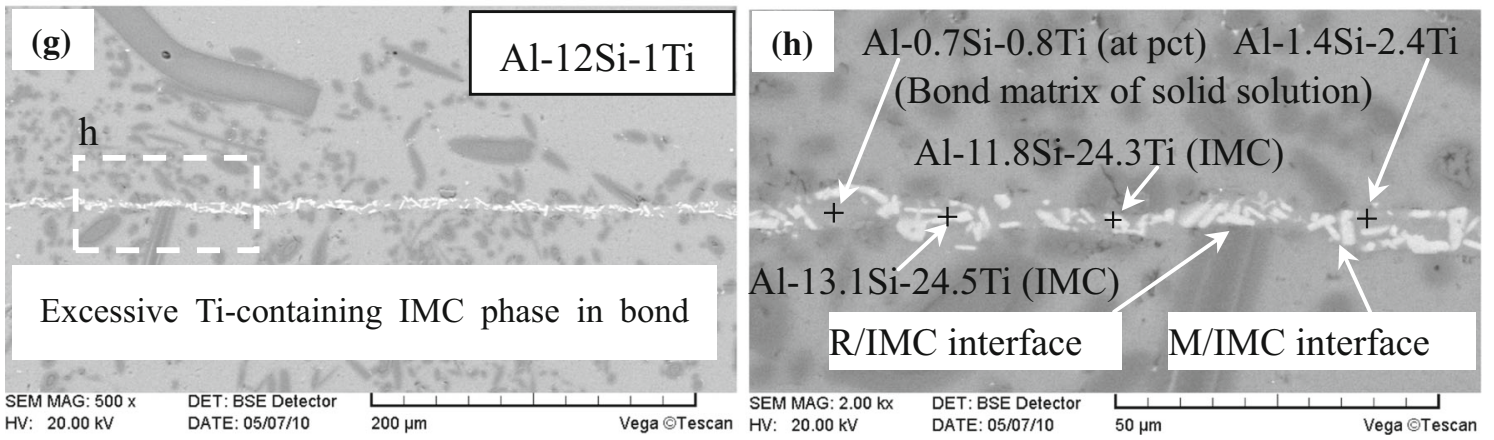

Fig. 4-Microstructures of joints prepared with different interlayers of Al-12Si- $x \mathrm{Ti}(x=0,0.1,0.5$, and $1 \mathrm{wt}$ pct) under high stress of $1 \mathrm{MPa}$ at $883 \mathrm{~K}\left(610^{\circ} \mathrm{C}\right)$ for $30 \mathrm{~min}: 0 \mathrm{Ti}(a, b) ; 0.1 \mathrm{Ti}(b, c) ; 0.5 \mathrm{Ti}(e, f)$; and $1 \mathrm{Ti}(g, h)$. 

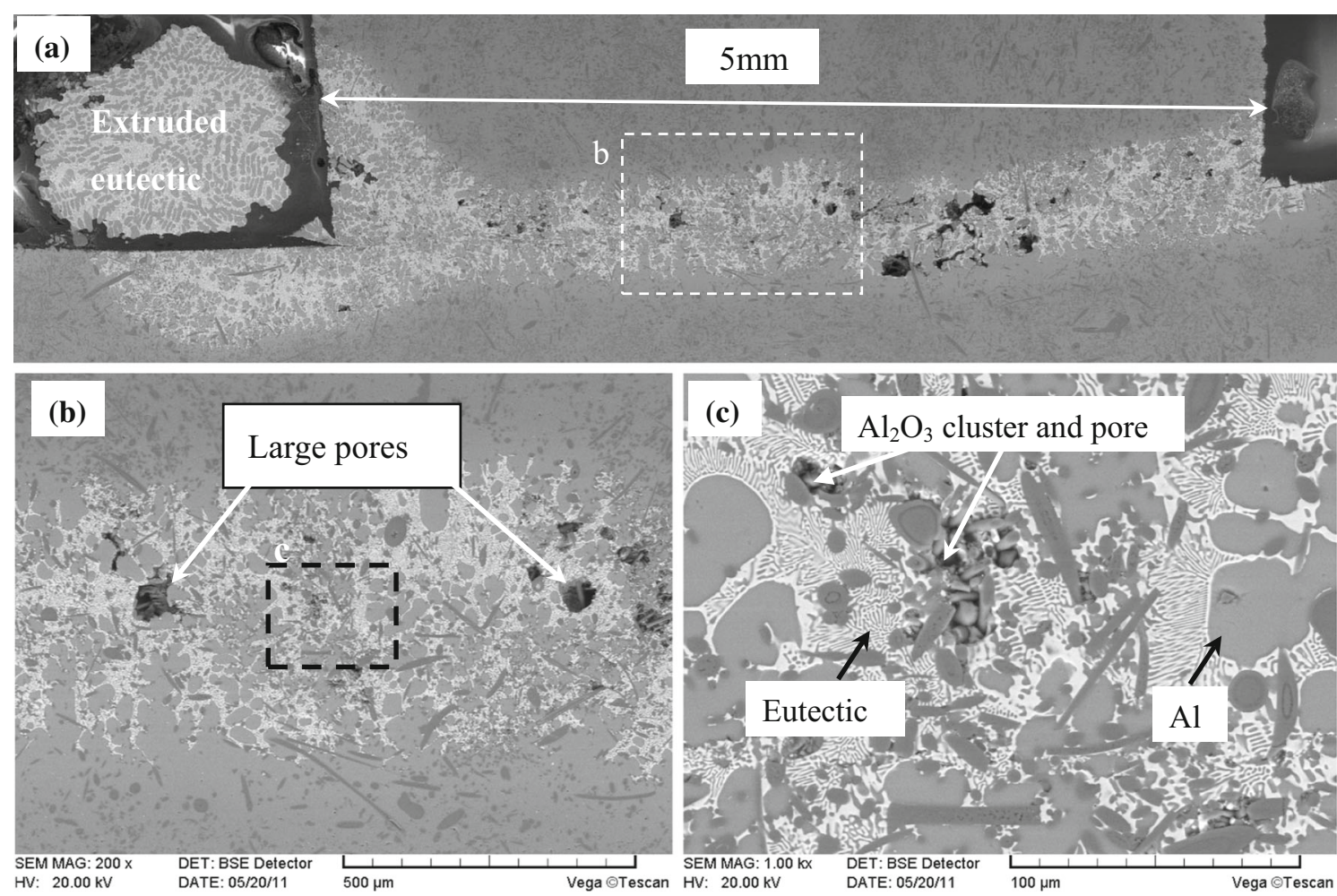

Fig. 5-BSE images of microstructure of the general TLP bonded joint using a popular Cu foil interlayer under the condition of 1 MPa $\times 30$ $\min \times 853 \mathrm{~K}\left(580^{\circ} \mathrm{C}\right)$ showing the disappearance of $\mathrm{M} / \mathrm{M}$ interface $(a)$, brittle eutectic-containing matrix and large pores $(b)$, and defects including short fiber cluster and small pores caused by poor wettability at the $\mathrm{R} / \mathrm{M}$ interface $(c)$.

bond seam thickness, (II) the kinds of phases in the bond seams, and (III) the resultant types of interface between the bond seam and the parent composite.

For the Al-12Si interlayer, the residual thickness of the bond seam was decreased from initial $100 \mu \mathrm{m}$ to about 0 $\mu \mathrm{m}$. Such an evidence of discharging of the molten Al-12Si out of the interface indicated that (I) the incubation time to start wetting reaction with $\mathrm{Al}$ matrix could not be reduced by pressure, although the pressure was able to break oxide film on the molten Al-12Si braze, and (II) a very thin layer of residual molten $\mathrm{Al}-12 \mathrm{Si}$ would isothermally solidify rapidly, terminating the wetting reaction at some liquid/solid microinterfaces. ${ }^{[15]}$ However, no gap was observed at the $\mathrm{R} / \mathrm{M}$ interface for the Al-12Si interlayer, even at 4000 times magnification. It should be attributed to creep deformation and interlocking at $\mathrm{M}$ / $\mathrm{M}$ interface at $883 \mathrm{~K}\left(610^{\circ} \mathrm{C}\right)$ under $1 \mathrm{MPa}$ and minor reaction at the $\mathrm{R} / \mathrm{M}$ interface. The latter could be possible because the presence of $\mathrm{SiO}_{2}$ in the reinforcement can significantly decrease the wetting reaction temperature from $1223 \mathrm{~K}\left(950{ }^{\circ} \mathrm{C}\right)$ for $\mathrm{Al} / \mathrm{Al}_{2} \mathrm{O}_{3}$ system to $973 \mathrm{~K}$ $\left(700{ }^{\circ} \mathrm{C}\right)$ for $\mathrm{Al} / \mathrm{SiO}_{2}$ system, facilitating the wetting at the $\mathrm{R} / \mathrm{M}$ interface.$^{[54]}$ However, the low bonding temperature of $883 \mathrm{~K}\left(610^{\circ} \mathrm{C}\right)$ limited the reaction degree, leading to limited wetting at the $\mathrm{R} / \mathrm{M}$ interface without detectable reaction products. Moreover, the possible reaction products of both $\mathrm{Al}_{2} \mathrm{O}_{3}$ and $\mathrm{Si}$ are difficult to distinguish from original ceramic phase and Al matrix by the BSE image. Based on the discharge of molten braze, low joining temperature, and poor spreading behavior on the composite substrate, ${ }^{[14]}$ it can be deduced that $\mathrm{Al}-12 \mathrm{Si}$ could not reliably wet the alumina-based reinforcement.

For Al-Si-Ti interlayer, the final microstructure can be characterized as follows: (1) no interfacial gap was observed and the active interlayer was not completely discharged, although the thickness of the bond seam was significantly decreased from 100 to $5 \mu \mathrm{m}$ under high pressure; (2) several short bar-like Ti-containing IMC phases ( 5 to $10 \mu \mathrm{m}$ in length and $\sim 2 \mu \mathrm{m}$ in thickness) in situ precipitated within the bond seam; (3) the volume fraction of the newly formed Ti-containing IMC phase increased with increasing Ti content, reaching a level much more than 30 vol pct, especially for the Al-12Si-1Ti interlayer; (4) the in situ formed Ti-containing IMC phase was also difficult to extrude from the joint interface under the bonding pressure; and (5) Ti was difficult to detect in the composite adjacent to the surface. Although the reaction products at the $\mathrm{R} / \mathrm{M}$ interface for any of the Ti-containing active interlayers were not detected, the presence of residual bond seam and the dense bond/composite interface confirmed that Al-12Si-1Ti had more favorable wettability over Al-12Si. Moreover, the presence of Ti-containing IMC phase within the bond seam and the absence of $\mathrm{Ti}$ in the composite adjacent to the surface showed that liquid $\mathrm{Ti}$ atoms tended to remain in the bond seam rather than to diffuse into solid Al matrix. The distribution feature of Ti could be explained by the little solubility of $\mathrm{Ti}$ in $\mathrm{Al}$, the slow diffusion rate in $\mathrm{Al}$ matrix, ${ }^{[55]}$ the bonding temperature lower than the melting point of $\mathrm{Al}$ matrix, and the precipitation nature 
of $\mathrm{Ti}$ in the form of aluminide from liquid phase during isothermal solidification. ${ }^{[47]}$

The EDS point analysis results showed that the Al-Si-Ti IMC phase belonged to Ti(AlSi $)_{3}$ phase with low Si content, which was less than 15 wt pct. ${ }^{[56]}$ In recent years, aluminide particles such as $\mathrm{NiAl}_{3}, \mathrm{FeAl}_{3}$, and $\mathrm{TiAl}_{3}$ were believed to be useful reinforcements for aluminum alloys to increase specific strength, specific modulus, or wear resistance at both ambient and elevated temperatures, ${ }^{[55,57]}$ and compared with most other aluminum-rich intermetallics, $\mathrm{Al}_{3}$ Ti is very attractive because it has a high melting point of $1623 \mathrm{~K}\left(1350{ }^{\circ} \mathrm{C}\right)$ and a relatively low density $\left(3.4 \mathrm{~g} / \mathrm{cm}^{3}\right) \cdot{ }^{[55]}$ Because the current Ti-containing IMC phase was successfully dispersed in the bond seam and had a similar size to the original $\mathrm{Al}_{2} \mathrm{O}_{3}$ short fiber reinforcement and a dense interface with the bond matrix (being solid solution after isothermal solidification and homogenization), it could act as an in situ reinforcement within the bond seam. ${ }^{[47]}$

Although the Al-Si-Ti phase can be considered to be a new kind of reinforcement, ${ }^{[56]}$ it should be noted that the presence of large amounts of the Al-Si-Ti phase gave rise to an interface between the ceramic reinforcement and the Al-Si-Ti phase (denoted as the R/IMC interface). The R/IMC interface should be weak because the Al-Si-Ti phase would crystallize from the liquid phase through concentration-precipitation-termination-engulfment of $\mathrm{Ti}$ with the aid of $\mathrm{Si}$ diffusion into $\mathrm{Al}$ matrix during isothermal solidification ${ }^{[47]}$ rather than nucleate at the ceramic reinforcement. Similarly, an interface between $\mathrm{Al}$ matrix and the Al-Si-Ti phase would present (denoted as the M/IMC interface). Thus, in the A-TLP joint produced with Al-12Si-1Ti, the four kinds of interfaces are $\mathrm{M} / \mathrm{M}, \mathrm{R} / \mathrm{M}, \mathrm{M} / \mathrm{IMC}$, and $\mathrm{R} /$ IMC.
Although the $\mathrm{M} / \mathrm{M}$ and $\mathrm{R} / \mathrm{M}$ were bonded intimately (no void at 4000 times magnification), the presence of $\mathrm{M} / \mathrm{IMC}$ and $\mathrm{R} / \mathrm{IMC}$ interfaces would counteract the effect of dense bonding at $\mathrm{M} / \mathrm{M}$ and $\mathrm{R} / \mathrm{M}$ interfaces because some of the strong $\mathrm{M} / \mathrm{M}$ and $\mathrm{R} / \mathrm{M}$ interfaces were replaced by numerous weak M/IMC and R/IMC interfaces, respectively, leading to the fracture along the M/IMC and R/IMC interfaces (Referring to Figure 8(h) showing the fracture path and Figure 9(b) showing the fracture surface in Section III-C).

Because of the more favorable wettability at the R/M interface and the presence of the in situ formed $\mathrm{Ti}(\mathrm{AlSi})_{3}$ within the bond seam in a medium amount, the A-TLP joint using Al-12Si-0.5Ti exhibited the maximum shear strength. In contrast, for the Al-12Si-1Ti interlayer, although it exhibited better wettability over other interlayers, the presence of excessive short bar-like Ti-containing IMC phase resulted in many weak M/ IMC and R/IMC interfaces, which led to a lower joint strength than that using $\mathrm{Al}-12 \mathrm{Si}$. The acceptable joint shear strength for Al-12Si should benefit from the limited wetting at some rough $\mathrm{M} / \mathrm{M}$ interfacial areas and mechanical interlocking at many $\mathrm{M} / \mathrm{M}$ and $\mathrm{R} / \mathrm{M}$ interfaces under high pressure.

Figure 5 shows the popular TLP-bonded joint using $50-\mu$ m-thick $\mathrm{Cu}$ foil interlayer at $853 \mathrm{~K}\left(580{ }^{\circ} \mathrm{C}\right)$ for 30 minutes under a pressure of $1 \mathrm{MPa}$. The wetting at the $\mathrm{M} / \mathrm{M}$ interface has been achieved well by the eutectic reaction, but the resultant eutectic layer was too thick, reaching $500 \mu \mathrm{m}$ because of the deep dissolution reaction. For this composite with medium $\mathrm{Al}_{2} \mathrm{O}_{3}$ volume fraction (generally produced by pressure casting), although no evident particle segregation was observed, the newly formed thick $\mathrm{Al}-\mathrm{Cu}$ eutectic liquid phase was difficult to extrude even under higher pressure.
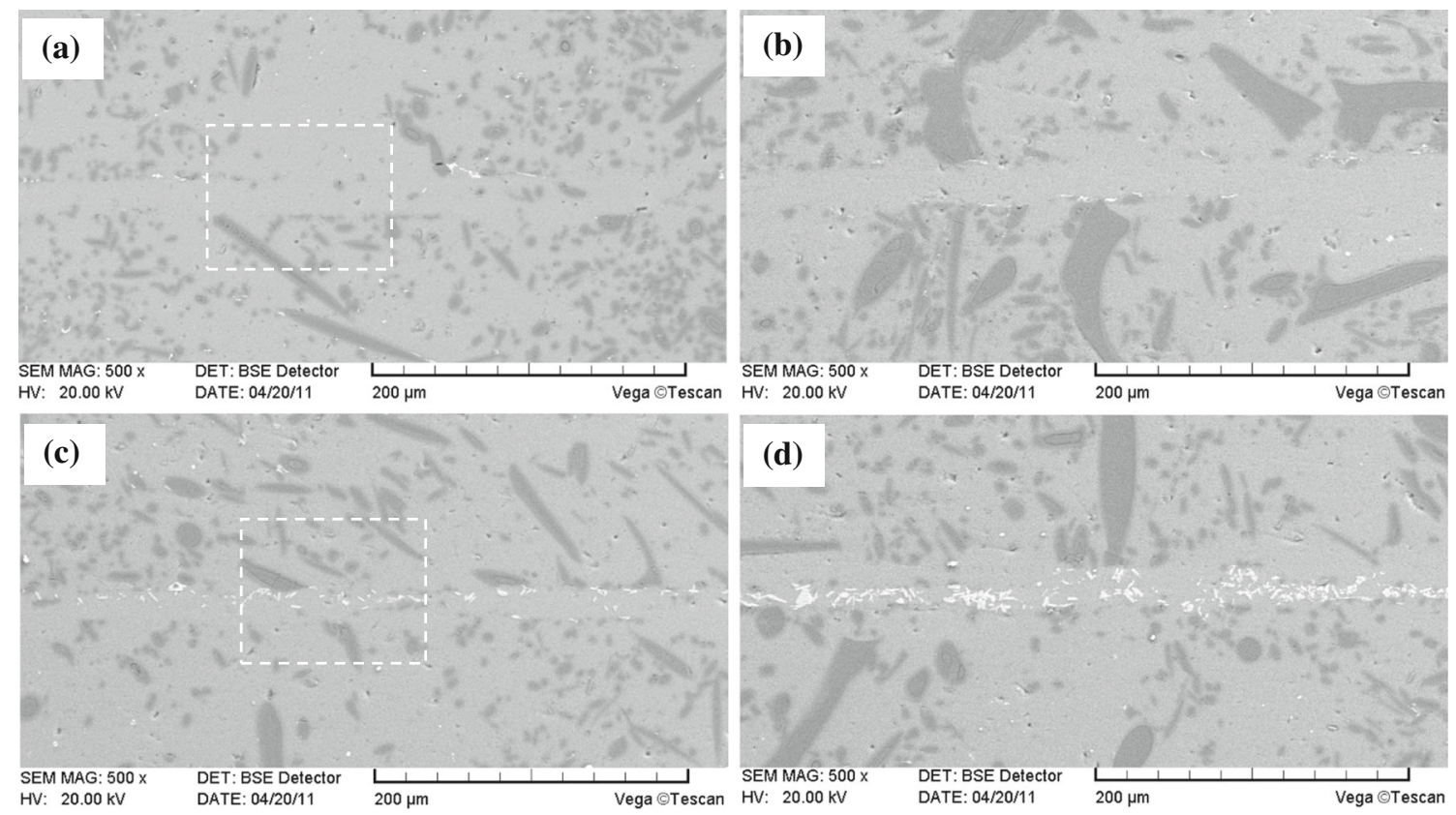

Fig. 6-Microstructures of joints prepared under low pressure of $0.015 \mathrm{MPa}\left[883 \mathrm{~K}\left(610^{\circ} \mathrm{C}\right) \times 30 \mathrm{~min}\right]$ showing the increase in bond seam thickness and the decrease in volume fraction of the in situ precipitated Ti-containing IMC phase within the bond seam compared with the case under $1 \mathrm{MPa}$ : (a) 0 pet Ti, (b) 0.1 pet Ti, (c) 0.5 pet Ti, and $(d) 1$ pet Ti. 
Additionally, in the vicinity of the interface, the presence of $\mathrm{Al}_{2} \mathrm{O}_{3}$ cluster and pores within the cluster demonstrated that the molten $\mathrm{Cu}$ exhibited poor wettability. Both the thick eutectic region and pore defects degraded the joint strength.

\section{Final microstructure under low pressure}

Figure 6 shows the microstructures of joints prepared using Al-12Si- $x \mathrm{Ti}(x=0,0.1,0.5$, and 1 in wt pct $)$ interlayers under low pressure of $0.015 \mathrm{MPa}$ after melting of the interlayers. Like the microstructure of joints brazed under $1 \mathrm{MPa}$, no particle segregation, void, or reaction products at the $\mathrm{R} / \mathrm{M}$ interface were observed for any of the interlayers, and the Al-Si-Ti IMC phase also existed within the bond seam. The low pressure resulted in the following beneficial effects. First, although the thickness of the bond seam changed from initial value of 100 to $\sim 25 \mu \mathrm{m}$, the final thickness was greater than that under high pressure of $1 \mathrm{MPa}$ by $\sim 20$ $\mu \mathrm{m}$. Second, the volume fraction of the in situ precipitated Ti-containing IMC phase within the bond seam decreased compared with that prepared under high pressure. The former was beneficial to (1) avoiding excessive discharging of the molten interlayer, thus achieving the dissolution of Al matrix and wetting at the $\mathrm{M} / \mathrm{M}$ interface; and (2) reducing the volume fraction of the in situ precipitated Ti-containing IMC phase within the bond seam. The latter was beneficial to decreasing the number of the $\mathrm{M} / \mathrm{IMC}$ and $\mathrm{R} / \mathrm{IMC}$ interfaces and then reducing the discontinuity in mechanical property at the final interface between the bond seam and composite.

The microstructure of the A-TLP joints using Al-12Si-0.5Ti under $0.015 \mathrm{MPa}$, which exhibited the maximum shear strength of $88.6 \mathrm{MPa}$ (99 pct of $89.3 \mathrm{MPa}$ of the as-cast $\mathrm{Al}_{2} \mathrm{O}_{3 \mathrm{sf}} / \mathrm{Al}$ composite), was specifically examined in higher magnification, as shown in Figure 7. Even at high magnification of 2000 and 40,000 times, no void was observed at the R/M interface as shown in Figures 7(a) and (b), indicating that the active Ti could improve the wettability at the $\mathrm{R} / \mathrm{M}$ interface, although $\mathrm{Ti}$ was not detected at the $\mathrm{R} / \mathrm{M}$ interface in the current work. For the in situ precipitated Ti-containing IMC phase within the bond seam, the EDS point analysis result showed that it had a composition of A1-18.6Ti-10.9Si (at. pct), so the IMC phase can be identified as $\mathrm{Ti}(\mathrm{A} 1 \mathrm{Si})_{3}$, i.e., a logogram of $\operatorname{Ti}\left(\mathrm{Al}_{1-x} \mathrm{Si}_{x}\right)_{3}$ with small $\mathrm{Si}$ content, $0 \leq x \leq 0.15$. $^{[56]}$ The $\operatorname{Ti}\left(\mathrm{Al}_{1-x} \mathrm{Si}_{x}\right)_{3}$ phase has been demonstrated by Zeren and Karakulak to have outstanding wear resistance in Al-Si- $x$ Ti cast alloy. ${ }^{[56]}$ Because (1) the Ti-containing IMC phase was so small, namely 2 to $5 \mu \mathrm{m}$ in length and $1 \mu \mathrm{m}$ in thickness (much smaller than short alumina fiber reinforcement) and dispersed uniformly, and (2) no

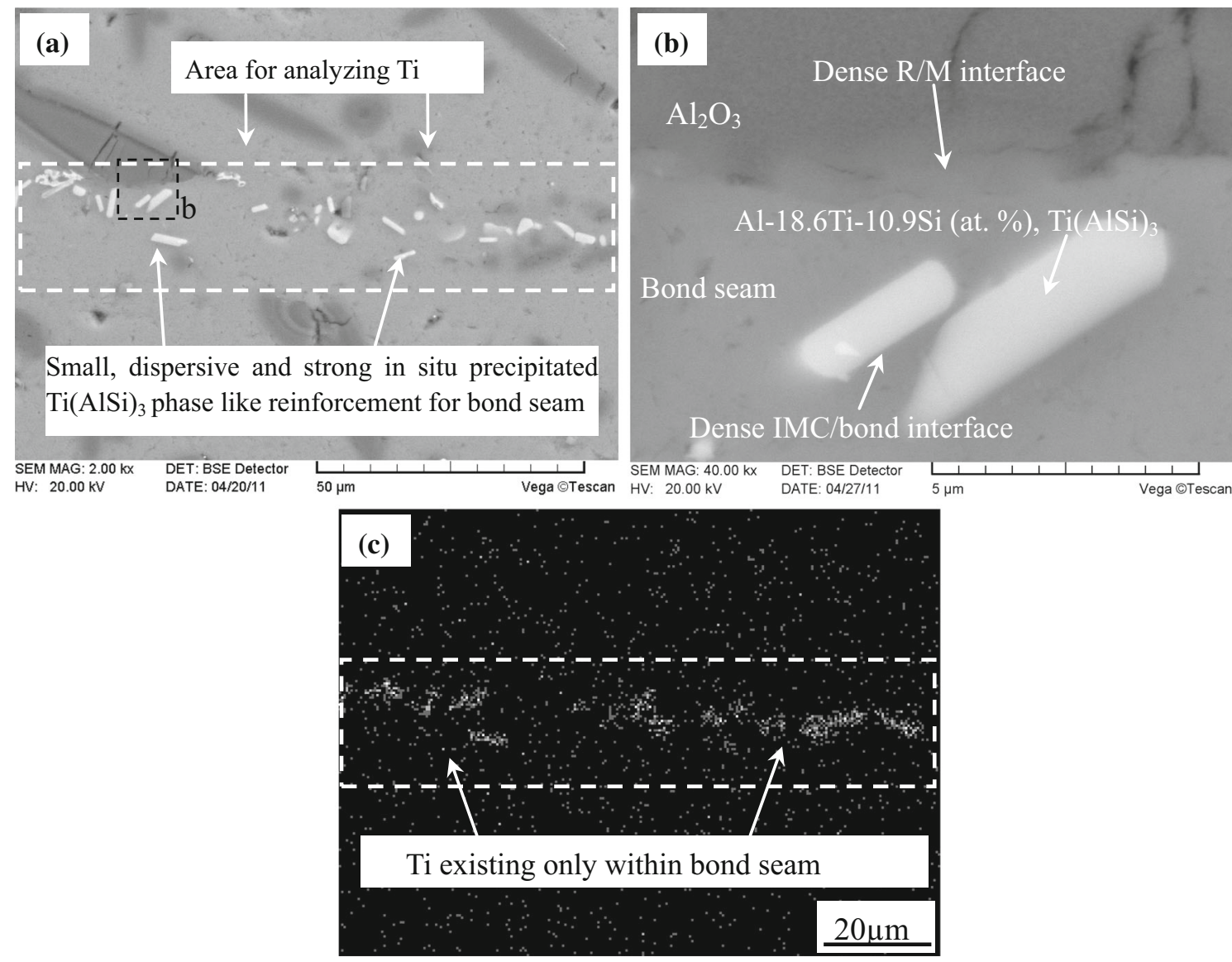

Fig. 7-Detailed microstructure of the A-TLP joint using Al-12Si-0.5Ti under low pressure showing dense R/M interface and the in situ precipitated Al-Si-Ti IMC phase (being small and dispersed) within the bond seam of solid-solution matrix after isothermal solidification. 

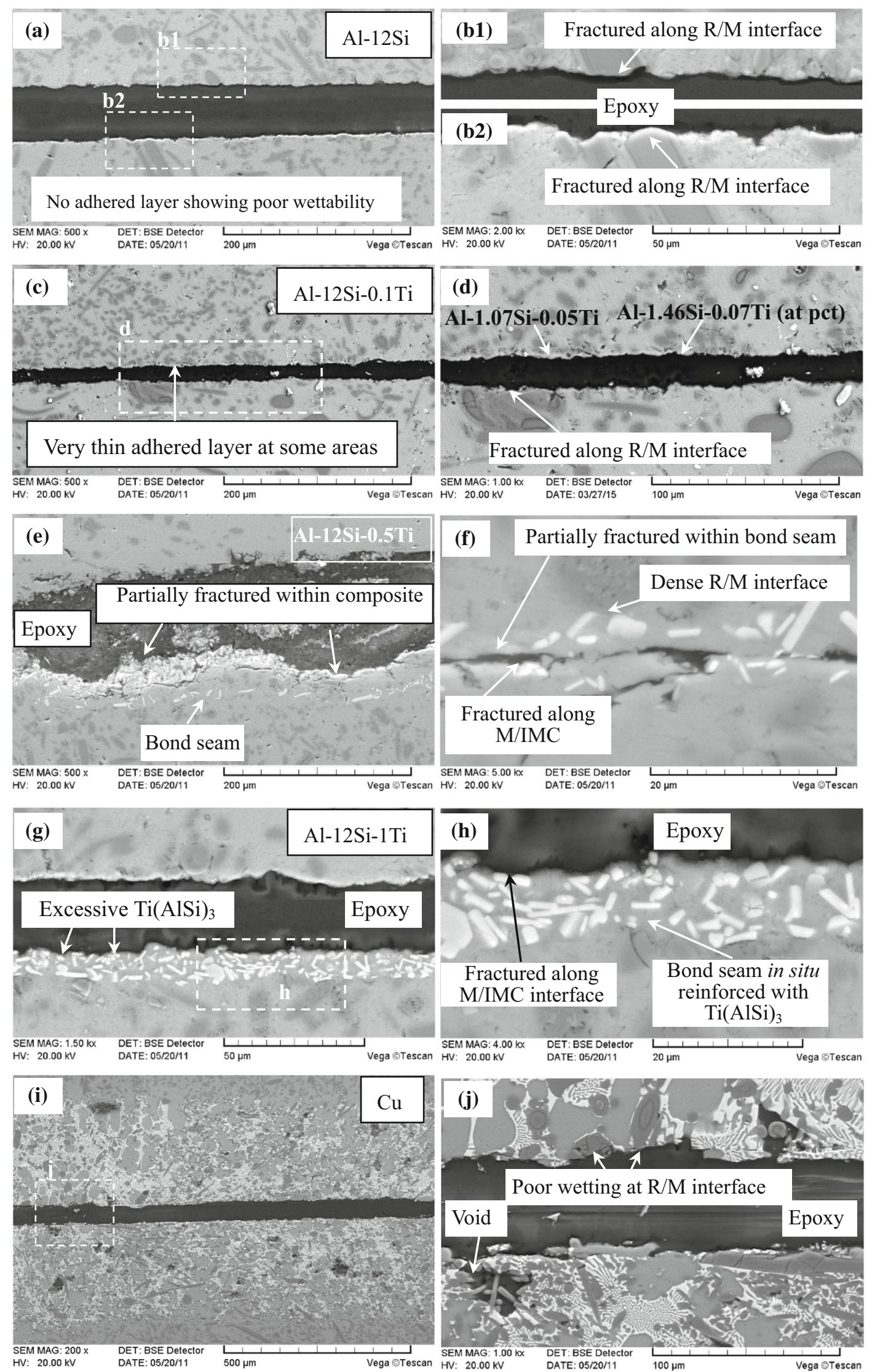

Fig. 8-Fracture path in the joints prepared under the condition of $883 \mathrm{~K}\left(610^{\circ} \mathrm{C}\right) \times 30 \mathrm{~min} \times 1 \mathrm{MPa}$ using different interlayers: $(a, b)$ Al-12Si, $(c, d) \mathrm{Al}-12 \mathrm{Si}-0.1 \mathrm{Ti},(e, f) \mathrm{Al}-12 \mathrm{Si}-0.5 \mathrm{Ti},(g, h) \mathrm{Al}-12 \mathrm{Si}-1 \mathrm{Ti}$, and $(i, j) \mathrm{Cu}$. 
void was observed at the IMC/bond seam matrix, the short IMC phase can act as an in situ reinforcement for bond matrix, which had become solid solution with little Si after isothermal solidification. Such an improvement in interface microstructure and the enhanced bond seam by the small, dispersed, and appropriate Ti-containing IMC phase (in situ precipitated) made the strength of the A-TLP joints higher.

\section{Fracture Behavior}

Besides joint microstructure, the effect of Ti addition on improvement of the joint shear strength can be also explained from the viewpoint of the joint fracture path, even under the high pressure of $1 \mathrm{MPa}$. As shown in Figure 8, there were four types of joint fracture paths depending on the $\mathrm{Ti}$ content: (1) flat and straight fracture path along the initial surface of the composite substrates without adhesion of interlayers of Al-12Si and Al-12Si-0.1Ti, (2) along the interface between enhanced bond seam and the Al-MMC for Al-12Si-1Ti, (3) mixed fracture path, within the matrix and/or bond seam of solid solution, for Al-12Si-0.5Ti, and (4) within the brittle $\mathrm{Al}-\mathrm{Cu}$ eutectic matrix containing short fiber clusters and pores for $\mathrm{Cu}$ foil. The results demonstrated that an appropriate addition of $\mathrm{Ti}$ in interlayers can improve the mechanical performance of joints by changing the fracture path from completely along initial interface to partially into the bond seam or the matrix.

In particular, it should be noted that in the joint prepared using Al-12Si-1Ti, no crack initiation and propagation occurred within the bond seam, showing that the bond seam was significantly reinforced by the newly in situ formed Ti(A1Si $)_{3}$ phase. To understand the effect of the newly in situ formed $\mathrm{Ti}(\mathrm{AlSi})_{3}$ phase on joint property and fracture behavior, the fracture surface of the joint using Al-12Si-1Ti was examined, as shown in Figure 9. Numerous short bar-like Al-Si-Ti phases with smooth surface could be seen on the adhered layer. The smooth surface of the Al-Si-Ti phase showed that the excessive newly formed Al-Si-Ti phase had negative effects, resulting in a fracture along the $\mathrm{M} /$ IMC or R/IMC interfaces.

When reducing pressure after melting of the interlayer, the fracture path can be improved to some extent. For Al-12Si, the filler metal could be retained as shown in Figure 10. The low pressure prevented the filler metal from discharging, resulting in a longer period to react with $\mathrm{Al}$ matrix at the $\mathrm{M} / \mathrm{M}$ interface and sound $\mathrm{M} / \mathrm{M}$ interface. As a result, the joint shear strength was improved by $8 \mathrm{MPa}$ more than that under high bonding pressure. However, the limited increase in shear strength, straight fracture path, and numerous bare ceramic reinforcements on the fracture surface suggested that the Ti-free Al-12Si interlayer was unable to improve the wettability at $\mathrm{R} / \mathrm{M}$ even for a longer interacting time under low pressure. For the A-TLP joint produced with an $\mathrm{Al}-12 \mathrm{Si}-0.5 \mathrm{Ti}$ active interlayer under low pressure, three types of favorite fracture modes appeared, as shown in Figure 11. In mode I, fracture occurred within the composite as shown in Figure 11(a); this type of fracture mode accounted for approximately 13 pct of total fracture path. In mode II, fracture took place in the bond seam as shown in Figure 11(b) and accounted for 27 pct of the whole fracture path. In mode III, fracture happened along the interface between the composite and the bond seam newly formed through matrix dissolution and isothermal solidification, which accounted for 60 pet.

Clearly, mode I and mode II together accounted for approximately 40 pct of the whole cross-section of the tested joint, indicating that the interface bonding strength at the 40 pct region of interface was superior to that of the solid-solution bond seam matrix and/or the parent composite. It can be seen from Figure 11(c) that the $\mathrm{Al}_{2} \mathrm{O}_{3}$ short fiber was pulled apart from the composite because of the high strength at the $\mathrm{R} / \mathrm{M}$ interface. The results demonstrated that the active $\mathrm{Ti}$ could improve the bonding at $\mathrm{R} / \mathrm{M}$ partly. In particular, it should be emphasized that the fracture path for Al-12Si-0.5Ti active interlayer could partially propagate
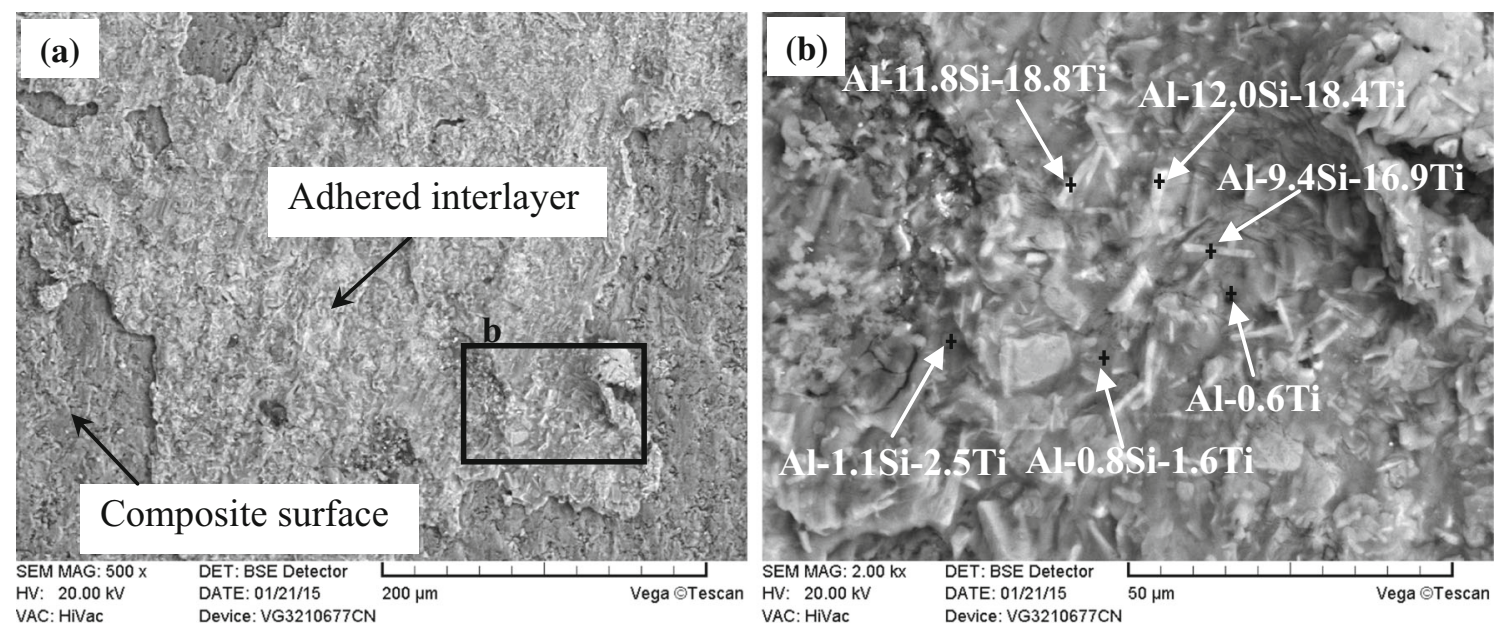

Fig. 9-Fracture surface of the A-TLP joint prepared with Al-12Si-1Ti showing the fracture path along the interface between bond seam and composite $(a)$ and the presence of numerous newly formed short bar-like Al-Si-Ti phase with smooth surface on fracture surface $(b)$. 

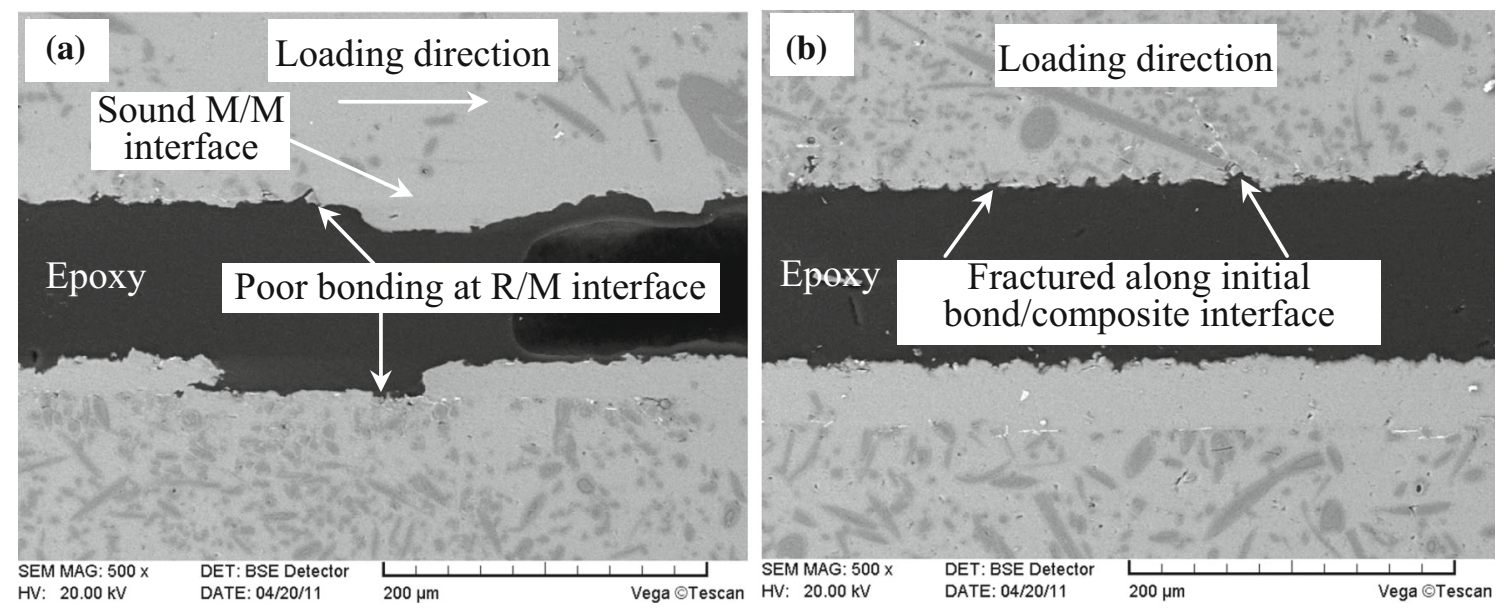

Fig. 10- BSE images of the fracture path in the joints prepared under the condition of $883 \mathrm{~K}\left(610^{\circ} \mathrm{C}\right) \times 30 \mathrm{~min} \times 0.015 \mathrm{MPa}$ using $\mathrm{Al}-12 \mathrm{Si}$ foil interlayer showing favorable joining at the $\mathrm{M} / \mathrm{M}$ interface and poor joining at the $\mathrm{R} / \mathrm{M}$ interface.
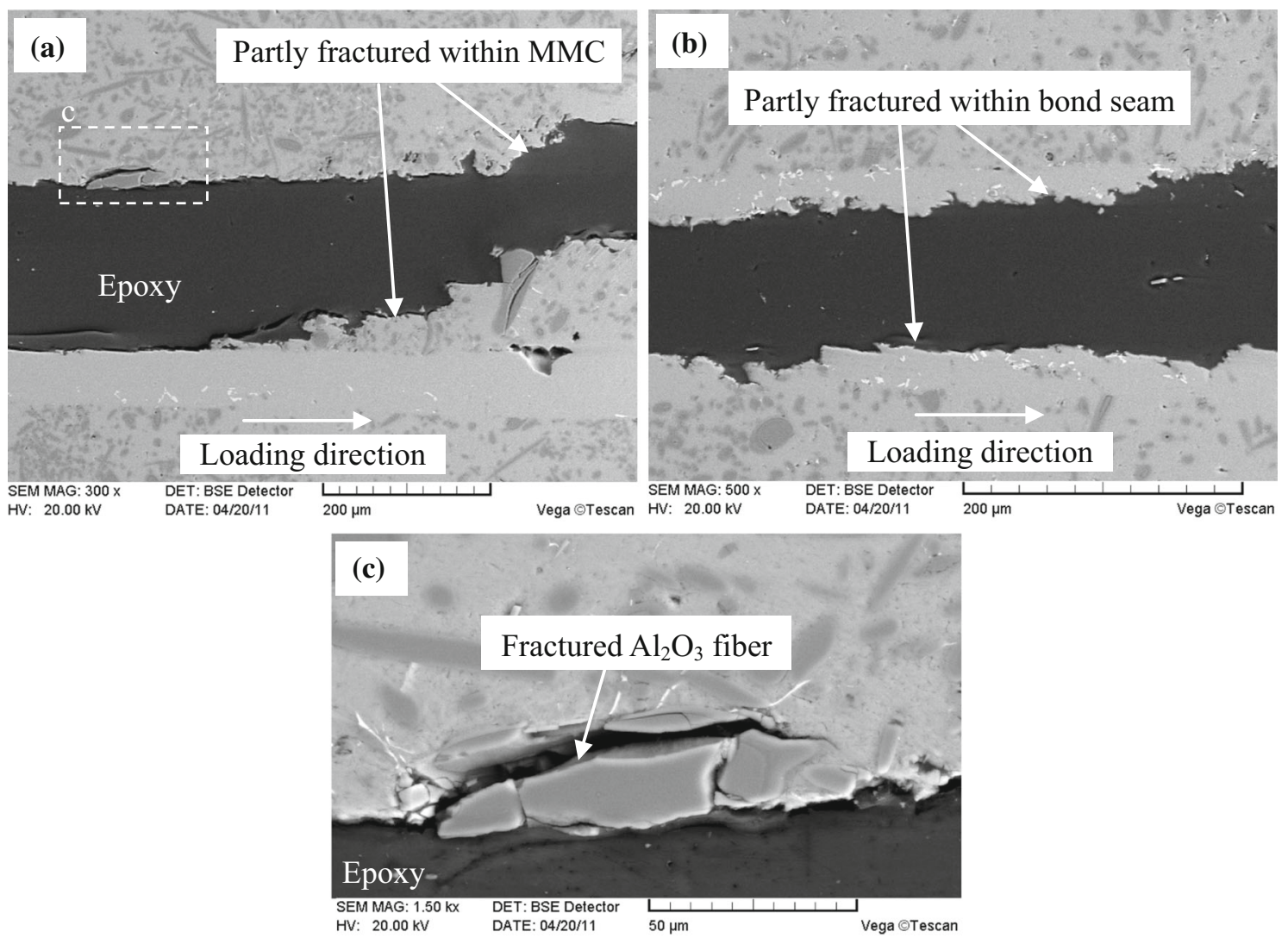

Fig. 11-BSE image of partial favorite fracture paths in the joint using Al-12Si-0.5Ti foil under low pressure showing different fracture modes: (a) within the composite and $(b)$ within bond seam of solid-solution matrix. $(c)$ A special example of strong interfacial bonding at $\mathrm{R} / \mathrm{M}$ interface leading to fracture of the $\mathrm{Al}_{2} \mathrm{O}_{3}$ short fiber reinforcement.

into the $\mathrm{Al}_{2} \mathrm{O}_{3 \mathrm{~s}} / \mathrm{Al}$ composite, indicating that both the interface joining and bond seam were enhanced well by improving wettability and the presence of in situ Al-Si-Ti phase, respectively. Moreover, reducing the pressure after melting of the interlayer could further improve the joint shear strength by avoiding liquid discharging during the incubation period, prolonging the liquid/solid reacting time for wetting and forming small and dispersive Ti-containing phase as in situ reinforcement with appropriate volume fraction in the bond seam.

\section{CONCLUSIONS}

To optimize both the interlayer composition design route and joining parameters for TLP bonding of the $\mathrm{Al}_{2} \mathrm{O}_{3 \mathrm{~s}} / \mathrm{Al}$ composite, the A-TLP bonding using 
Al-12Si- $x \operatorname{Ti}(x=0,0.1,0.5$, and 1$)$ system active fillers was performed under different pressures. By comparing the joint microstructure, shear strength, and fracture behavior, the conclusions can be summarized as follows:

1. The improvement in wettability by adding $\mathrm{Ti}$ as active element were confirmed by reduction of expulsion of liquid interlayer (reduced to $5 \mu \mathrm{m}$ under $1 \mathrm{MPa}$ and $25 \mu \mathrm{m}$ under $0.015 \mathrm{MPa}$ ), elimination of interfacial gap, higher shear strength (by $\sim 15 \mathrm{MPa}$ ), and favorable fracture path (partially through bond seam and the composite).

2. The added Ti was difficult to detect in the composite adjacent to the interface, and it tended to precipitate in situ within the bond seam in the form of short bar-like Al-Si-Ti IMC phase of Ti(AlSi $)_{3}$ with a small Si content. The nature of small size $(\sim 5 \mu \mathrm{m})$ and dispersive distribution of the in situ precipitated $\mathrm{Ti}(\mathrm{AlSi})_{3}$ IMC phase suggested that it could act as an in situ formed reinforcement for the bond seam matrix of solid solution after isothermal solidification. So, both the interfacial bonding and bond seam were enhanced by adding $\mathrm{Ti}$ in trace levels $(0.5 \mathrm{wt} \mathrm{pct})$.

3. The remaining Al-12Si liquid was finally able to increase joint shear strength, showing that there was an incubation period for wetting. Unlike popular TLP bonding using a $\mathrm{Cu}$ interlayer, when using an interlayer with a melting point lower than bonding temperature for joining Al-MMCs with poor wettability, reducing bonding pressure after melting of the interlayer was beneficial to the holding melt, prolonging the dissolution period of Al matrix, dispersing the in situ precipitated $\mathrm{Ti}(\mathrm{AlSi})_{3}$ IMC phase, and further improving joint shear strength.

4. Although high Ti addition (1 wt pet) could significantly improve the wettability and enhance the bond seam matrix, the joint shear strength decreased because of the presence of excessive $\mathrm{M} / \mathrm{IMC}$ and $\mathrm{R} /$ IMC interfaces.

5. The maximum shear strength of $88.6 \mathrm{MPa}$, which is extremely close to that of the as-cast composite of 89.3 MPa (up to 99 pct efficiency), was obtained when using the active interlayer containing medium Ti content $(0.5 \mathrm{wt} \mathrm{pct})$ and a low pressure after melting interlayer $(0.015 \mathrm{MPa})$. In principle, retaining molten active interlayer in a required amount and for a required time (depending on volume fraction of ceramic reinforcement and incubation period) is essential to obtaining sound joint.

\section{ACKNOWLEDGMENTS}

The current research was supported by the National Science Foundation of China (Nos. 51275390 and 50875199) and partially supported by China Scholarship Council (CSC). The first author also greatly acknowledges Professor Yasuo Takahashi at Joining and Welding Research Institute, Osaka University, Japan, for his kind support at the manuscript preparation stage.

\section{OPEN ACCESS}

This article is distributed under the terms of the Creative Commons Attribution 4.0 International License (http://creativecommons.org/licenses/by/4.0/), which permits unrestricted use, distribution, and reproduction in any medium, provided you give appropriate credit to the original author(s) and the source, provide a link to the Creative Commons license, and indicate if changes were made.

\section{REFERENCES}

1. A. Ureña, M.D. Escalera, and L. Gil: Compos. Sci. Technol., 2000, vol. 60, pp. 613-22.

2. D. Storjohann, O.M. Barabash, S.S. Babu, S.A. David, P.S. Sklad, and E.E. Bloom: Metall. Mater. Trans. A, 2005, vol. 36A, pp. $3237-47$

3. M.B.D. Ellis: Int. Mater. Rev., 1996, vol. 41, pp. 41-58.

4. Y.C. Lei, H.L. Xue, W.X. Hu, Z.Z. Liu, and J.C. Yan: Sci. Technol. Weld. Join., 2011, vol. 16 (7), pp. 575-80.

5. D. Wang, Q.Z. Wang, B.L. Xiao, and Z.Y. Ma: Mater. Sci. Eng. A, 2000, vol. 589, pp. 271-74.

6. A. Ureña, J.M.G. De Salazar, M.D. Escalera, and M.I. Fernandez: Weld. J., 1997, vol. 76 (2), pp. 92s-102s.

7. XP Zhang, GF Quan, and W Wei: Compos. Part. A, 1999, vol. 30 (6), pp. 823-27.

8. A. Suzumura and Y.J. Xing: Prepr. Natl. Meet. JWS, 1994, vol. 55, pp. 282-83.

9. A. Ureña, L. Gil, E. Escriche, J.M. Gomez de Salazar, and M.D. Escalera: Sci. Technol. Weld. Join., 2001, vol. 6 (1), pp. 1-11.

10. J.C. Yan, H.B. Xu, L. Shi, X.H. Wang, and S.Q. Yang: Sci. Technol. Weld. Join., 2008, vol. 13 (8), pp. 760-64.

11. Z.W. Xu, J.C. Yan, and S.Q. Yang: Mater Sci. Eng. A, 2006, vol. 415A (1-2), pp. 80-86.

12. H.B. Xu, Q.X. Xing, Y.L. Zeng, Y. Luo, and C.H. Du: Sci. Techol. Weld. Join., 2011, vol. 16 (6), pp. 483-87.

13. W.P. Weng and T.H. Chuang: Metall. Mater. Trans. A, 1997, vol. 28A, pp. 2673-82.

14. A. Suzumura, Y. Xing, K. Takahashi, and T. Onzawa: Prepr. Natl. Meet. JWS, 1993, vol. 52, pp. 166-67.

15. A. Suzumura, M. Matsumoto, and Y. Xing: Prepr. Natl. Meet. JWS, 1996, vol. 59, pp. 262-63.

16. A. Suzumura, Y. Xing, and K. Takahashi: Prepr. Natl. Meet. JWS, 1993, vol. 53, pp. 326-27.

17. H. Kokawa, K. Mitsuzuka, and T. Kuwana: Prepr. Natl. Meet. JWS, 1993, vol. 52, pp. 176-77.

18. J.S. Zou, R.Q. Xu, Q.Z. Zhao, and Z. Chen: China Weld., 2003, vol. 12 (2), pp. 107-11.

19. J.S. Zou, R.Q. Xu, Q.Z. Zhao, and Y.S. Han: Mater. Dev. Appl., 2003, vol. 18 (4), pp. 5-12.

20. J. Niu, X. Luo, H. Tian, and J. Brnic: Mater Sci. Eng. B, 2012, vol. 177 (19), pp. 1707-11.

21. T. Enjo, K. Ikeuchi, Y. Murakami, and N. Suzuki: Trans. JWRI, 1987, vol. 16 (2), pp. 285-92.

22. R. Klehn and T.W. Eagar: WRC Bull., 1993, vol. 385, pp. 1-26.

23. Z. Li, Y. Zhou, and T.H. North: J. Mater. Sci., 1995, vol. 30 (12), pp. $1075-82$.

24. A.A. Shirzadi and E.R. Wallach: Mater. Sci. Technol., 1997, vol. 13 (2), pp. 135-42.

25. A. Suzumura and Y.J. Xing: Mater Trans. JIM, 1996, vol. 37 (5), pp. $1109-15$.

26. J.R. Askew, J.F. Wilde, and T.I. Khan: Mater. Sci. Technol., 1998, vol. 14 (9-10), pp. 920-24.

27. W.F. Gale and D.A. Butts: Sci. Technol. Weld. Join., 2004, vol. 9 (4), pp. 283-300.

28. Y. Shen, W.F. Gale, J.W. Fergus, and X. Wen: Mater. Sci. Technol., 2001, vol. 17 (10), pp. 1293-98.

29. Z.W. Xu, J.C. Yan, B.Y. Zhang, X.L. Kong, and S.Q. Yang: Mater. Sci. Eng. A, 2004, vol. 415, pp. 80-86.

30. Z.W. Xu, J.C. Yan, G.H. Wu, X.L. Kong, and S.Q. Yang: Compos. Sci. Technol., 2005, vol. 65 (13), pp. 1959-63. 
31. Z.W. Xu, J.C. Yan, C. Wang, and S.Q. Yang: Mater. Chem. Phys., 2008, vol. 112 (3), pp. 831-37.

32. Y. Zhou, W.F. Gale, and T.H. North: Int. Mater. Rev., 1995 , vol. 40 (5), pp. 181-96.

33. G.O. Cook, III and C.D. Sorensen: J. Mater. Sci., 2011, vol. 46, pp. 5305-23.

34. I. Tuah-poku, M. Dollar, and T.B. Massalski: Metall Trans. A, 1988, vol. 19, pp. 675-86.

35. W.H. Liu, D.Q. Sun, S.S. Jia, and X.M. Qiu: Trans. China Weld. Inst., 2003, vol. 24 (5), pp. 13-16.

36. J. Yan, Z. Xu, G. Wu, and S. Yang: Scripta Mater., 2004, vol. 51, pp. $147-50$.

37. J. Maity and T.K. Pal: J. Mater. Eng. Perform., 2012, vol. 21 (7), pp. $1232-42$.

38. K.O. Cooke, T.I. Khan, and G.D. Oliver: Metall. Mater. Trans. B, 2013, vol. 44B, pp. 722-29.

39. J. Yan, Z. Xu, S. Lei, X. Ma, and S. Yang: Mater. Des., 2011, vol. 32, pp. 343-47.

40. K.O. Cooke: Metall. Mater. Trans. B, 2012, vol. 43B, pp. 627-34.

41. W.P. Weng and T.H. Chuang: Mater. Manuf. Process., 1997, vol. 12 (6), pp. 1107-32.

42. E. Lugscheider, S. Ferrara, H. Janssen, A. Reimann, and B. Wildpanner: Microsyst. Technol., 2004, vol. 10 (3), pp. 233-36.

43. E. Lugscheider and S. Ferrara: Adv. Eng. Mater., 2004, vol. 6 (3), pp. $160-63$.

44. J. Huang, Y. Dong, Y. Wan, X. Zhao, and H. Zhang: J. Mater. Process. Technol., 2007, vol. 190, pp. 312-16.
45. G.F. Zhang, J.X. Zhang, Y. Pei, S.Y. Li, and D.L. Chai: Mater. Sci. Eng. A, 2008, vol. 488, pp. 146-56.

46. G.F. Zhang, B. Chen, M.Z. Jin, and J.X. Zhang: Mater. Trans., 2015, vol. 56 (2), pp. 212-17.

47. G.F. Zhang, X.J. Liao, B. Chen, L.J. Zhang, and J.X. Zhang: Metall. Mater. Trans. A., 2015, vol. 46A, pp. 2568-78.

48. G.F. Zhang, W. Su, J.X. Zhang, and A. Suzumura: J. Mater. Eng. Perform., 2013, vol. 22 (7), pp. 1982-94.

49. S. Ren, C. He, X. Qu, and Y. Li: J. Alloys Compd., 2008, vol. 455, pp. 424-31.

50. J.C. Lee, J.P. Ahn, Z. Shi, J.H. Shim, and H.I. Lee: Metall. Mater. Trans. A, 2005, vol. 36A, pp. 3237-47.

51. W.M. Zhong, G. L'espérance, and M. Suéry: Metall. Mater. Trans. A, 1995, vol. 26A, pp. 2637-49.

52. G.F. Zhang, W. Su, J.X. Zhang, and A. Suzumura: Trans Nonferrous Met. Soc. China, 2012, vol. 22 (3), pp. 596 603.

53. K. Kotani, J.P. Jung, K. Ikeuchi, and F. Matsuda: Trans. JWRI, 1999, vol. 28 (2), pp. 27-37.

54. P. Shen, H. Fujii, T. Matsumoto, and K. Nogi: Metall. Mater. Trans. A, 2004, vol. 35A, pp. 583-88.

55. C.J. Hsu, C.Y. Chang, P.W. Kao, N.J. Ho, and C.P. Chang: Acta Mater., 2006, vol. 54, pp. 5241-49.

56. M. Zeren and E. Karakulak: J. Alloys. Compd., 2008, vol. 450, pp. 255-59.

57. Y. Watanabe, N. Yamanaka, and Y. Fukui: Metall. Mater. Trans. A, 1999, vol. 30A, pp. 3253-61. 